\title{
Evaluation of Serum Iron, Zinc and Their Relationships with Glycemic Control Status in Iranian Elderly Women with Type 1 Diabetes Mellitus
}

\author{
Mahshid Mohammadian ${ }^{1}$, Attabak Toofani Milani ${ }^{1}$, Mohammad Reza Hassas ${ }^{3}$, Siamak Rashidi ${ }^{2}$, Elmira Roshani \\ Asl $^{1}$, Sadegh Rostaminasab ${ }^{4}$, Mohadeseh Nemati ${ }^{1}$, Farid Javandust ${ }^{1}$, Narmin Mokarizadeh ${ }^{1}$ and Farhad fathi \\ younesi ${ }^{2}$ \\ 1. Department of Biochemistry, Urmia University of Medical Sciences,Urmia 57147, West Azerbaijan, Iran \\ 2. Aria Medical Laboratory, Urmia University of Medical Sciences, Sanandaj 6618634683, Kurdistan, Iran \\ 3. Department of Medicine, Urmia University of Medical Sciences,Urmia 57147, West Azerbaijan, Iran \\ 4. Department of Biochemistry, Faculty of Medicine, Shahid Beheshti University of Medical Sciences, Tehran 1985717443, Tehran, \\ Iran
}

\begin{abstract}
It seems that defects on micro-minerals levels have an etiologic role involved in type 1 diabetes mellitus pathogenicity. The aim of our study were to evaluate the serum levels of zinc and iron and investigate their possible relationship between these biochemical parameters with demographic conditions and glycemic control in patients with type 1 diabetes mellitus disorder. In this case-control based study , 68 female with type 1 diabetes mellitus with a mean age of $52.2 \pm 2$ as case group and 122 healthy women as a control group with a mean age of $49 / 4 \pm 3 / 2$ were investigated for biochemical analysis, $10 \mathrm{~mL}$ fasting venous blood sample were obtained from each subjects. FBS (fasting blood glucose), fructosamine (glycemic control parameter) were determined (spectrophotometry method, (pars azmoon, Iran), nitroblue tetrazoline method respectively).serum zinc level with colorimetric method (Biorex-UK) and serum iron with photometric method (pars azmoon, Iran) were determined. Statistical analysis using SPSS software performed. Significant levels considered as $P<0.05$. According to this study there is statistically significant difference between serum levels of iron and zinc in patients with type 1 diabetes compared to controls .indeed serum level of iron and zinc had lower level in patient group toward controls. In patients group, there are a positive correlation between age and decreased level of serum zinc $(P<0.05)$. Also there was a significant negative correlation between the glycemic control status and serum zinc. Other studied parameters concluded BMI (body mass index), Weight and height have not significant difference between groups. The decrease in serum iron and zinc level in women with type 1 diabetes may be related to low dietary intake or increased excretion of micro minerals or the presence of confounding factors that require more extensive intervention studies to confirm it.
\end{abstract}

Key words: Type1 diabetes mellitus, Iron, Zinc, glycemic control, Iran.

\section{Introduction}

TIDM.1 (diabetes mellitus type I) or Insulin dependent diabetes, is an auto immune disease from Multi factorial interaction arising such as immune system, genetics and environments [1]. In fact, its property is distraction of $B$ cells with presence of

Corresponding author: Mahshid Mohammadian, Ph.D., research fields: biochemistry, pharmacology, cellular and molecular biology. E-mail: mohammadian_mahshid1365@yahoo.com. antibody against Islets of Langerhans cells, GADA (glutamic and decarboxylase-65) and IAA (tyrosine phosphatase) [2-5].

Patients with TIDM: are likely to get other Autoimmune and metabolic disorders and effects on their prognosis Trace elements are part of essential nutritious materials that is necessary in little amount for body with various metabolic actions. These elements including metals such as Iron, Copper, Zinc, Manganese, Magnesium and Vanadium. Trace 
elements are necessary for appropriate growth and development and correct physiologic work of organs [6-11].

Changes in metabolism of these elements may change glycemic condition that in some cases these problems exacerbate complications of diabetes or adverse effects of uncontrolled disease.

It seems defects of micro minerals are an etiologic factor for T1DM or is caused by the disease [12]. Fe (Iron) is a mineral material necessary for the production of important functional proteins such as hemoglobin and myoglobin which have a vital role in the transfer of oxygen molecules. The part of the Iron in the bloodstream is transferred in to the cell by a glycoprotein molecule called transferrin $[13,14]$. That according to many studies serum Iron level changes is observed in patients with diabetes $[15,16]$.

The $\mathrm{Zn}$ (Zinc) is an essential nutritious material which have a role in the function of hundreds of enzymes as well as in the metabolism, secretion and activity of insulin as effective antioxidant $[17,18]$. In most cases symptoms of Zinc deficiency in not appeared [19].

Due to the lack of Zinc storage, it is essential to daily consumption and access at cell to it is regulated Zinc is considered in metabolic diseases (e.g. Insulin resistance, metabolic syndrome, diabetes mellitus) because of the two major reasons : first, its role in the stability at insulin hexamer [20, 21]. And storing hormone in the pancreas and secondly its role as antioxidants in oxidative stress that are the main causes of the onset and progression of insulin resistance and diabetes [22-24]. By reducing the intracellular Zinc, insulin secretion decreases, resulting in increased glucose levels thus Langerhans islet cells are susceptible to injuries. Another factor that may Zinc reduction in diabetic patients is decreasing in Zinc absorption due to consumption of white meat instead of red meat (to reduce the absorption of saturated fatty acid). Evaluation at microelements such as Iron and Zinc in patients with diabetes is a significant issue that can affect the disease process and the issues involved in the disease. These effects can be evaluated by examining the glycemic status in the patients.

According to the importance of improving glycemic status to reduce the risk of late complication of diabetes and keep blood sugar levels within the normal range or close to normal, it is essential to assess the performance of glucose control quickly and accurately $[25,26]$.

Fructoseamine (glycemic plasma proteins) assessment as glycemic control for T1DM patients applicated as answer to changes in blood glucose. Fructoseamine levels and $\mathrm{HbA}_{1 \mathrm{c}}$ (glycosylated hemoglobin) are appropriate indicators for estimating blood glucose and diabetes complications. Therefore, in this study we reviewed Iron and Zinc micromineral elements and glycemic control status and the relationship between them in elderly woman with T1DM.

\section{Materials and Methods}

In this case-control study concluded 68 female patients with type I diabetes were referenced to aria medical laboratory located in sanandaj city with a mean age of $52.2 \pm 2$ as a patient group and 122 healthy woman as a control group with average age $49.4 \pm 3.2$ were considered .

After clinical examination and diagnosis at diabetic patients fasting venous blood was collected for laboratory examinations by clinical consultant.

From every patient $10 \mathrm{~mL}$ of blood sample were taken. Five $\mathrm{ml}$ was poured in to the tube containing EDTA anticoagulant and five milliliters was poured in to the non-contained anticoagulant tube to obtain serum. Isolation of serum from clot sample within a maximum of one hour after sample taking with centrifuges was done and after that serum specimens were stored at $-20{ }^{\circ} \mathrm{C}$ until use.

In order to evaluate serum Iron level, pars azmoon Iron kit by the photometric method (using Ferene) 
were utilized.

Fasting blood glucose by using glucose oxidase-parse Asmoon kit based on photometric method was measured. Serum zinc via Biorex-UK kit with colorimetric method assayed.

Fructoseamine test is based on measurement of glycosylated proteins in serum and since Albumin is the major protein in serum, this test can indicate level of glycated albumin in the body. Half life of albumin in the blood is about 20 days and that for plasma fructoseamin levels may indicate average blood glucose changes in 2-3 weeks. This test can show recent rapid changes in blood sugar in response to treatment or regiment therapy in diabetics within 2-3 weeks.

So in short term studies Fructoseamine test is preferred than test determining $\mathrm{A}_{1 \mathrm{C}}$ amount. Therefore in this study Fructoseamine parameter was measured. Fructoseamine were assessed by Nitro-blue Tetrazulyn. The results were analyzed with the manufacturer's normal values.

For statistical analysis the results were used in order to compare quantitative parameters of the study in patient group with control group, version 21 Spss software and independent T-test method were used. Results are show as mean \pm standard deviation. Significance level is considered $>0.05$.

\section{Results}

Demographic and biochemical characteristics of a T1DM patients population (mean age $(52.2 \pm 2)$ ) compared to healthy subjects (mean age $(49.4 \pm 3.2)$ ) were presented in Table 1.

The mean serum Iron, Zinc and parameters of glycemic control (fasting plasma glucose and fructoseamine in two group of patient and control are shown in Table 2.

Based on results Serum Iron level in patients with T1DM was significantly lower than control group. In analysis using T-test, there was statistically significant difference between the two groups $(P<0.05)$. Mean
Table 1 Demographic parameters comparison in patient and control groups.

\begin{tabular}{llll}
\hline$P$ value & *Controls & *Patients $\mathrm{N}=$ & Parameters \\
$P<0.05$ & $\mathrm{~N}=122$ & 68 & \\
$P<0.05$ & $69 \pm 2.4$ & $27.9 \pm 3.4$ & BMI $\left(\mathrm{Kg} / \mathrm{m}^{2}\right)$ \\
$P<0.05$ & $161 \pm 7.2$ & $75 \pm 6.2$ & Weight $(\mathrm{Kg})$ \\
$P<0.05$ & $49.4 \pm 3.2$ & $52.2 \pm 2$ & Age (year) \\
\hline
\end{tabular}

BMI: Body mass index.

*Data presented as mean \pm standard deviation.

Table 2 Biochemical parameters comparison between the two group of patient and control.

\begin{tabular}{llll}
\hline$P$ value & *controls $\mathrm{N}=$ & *Patients & Parameters \\
& 122 & $\mathrm{~N}=68$ & \\
$P<0.05$ & $129.01 \pm 41.8$ & $102.92 \pm 36.1$ & Iron mg/dl \\
$P<0.05$ & $89.81 \pm 11.90$ & $116.03 \pm$ & Zinc mg/dl \\
$P<0.05$ & $78.9 \pm 9.1$ & $160.2 \pm 4.6$ & FBS mg/dl \\
$P<0.05$ & $320 \pm 6.1$ & $529.3 \pm 28.7$ & $\begin{array}{l}\text { Fructoseamine } \\
\mu \mathrm{mol}\end{array}$ \\
\hline
\end{tabular}

FBS: Fasting blood sugar.

*Data presented as mean \pm standard deviation.

serum Zinc level in patient and control groups. After checking serum Zinc levels in patients with type 1 diabetes, there was significant lower zinc level in compared to control group $(P<0.05)$.

In Pearson correlation analysis results shown positive relationship between age and decreased Zinc level in this study $(P<0.05)$. The test did not show correlation between the age and other parameters $(P>$ $0.05)$. Our data shown negative relationship between glycemic control parameters (fructoseamine and fasting blood sugar level) and serum Zinc level in patient with type 1 diabetes $(P<0.05)$. Result showed there is a relationship between smoking and decrease serum levels of Iron and Zinc in diabetic women.

\section{Discussion}

In this study patients with type 1 diabetes in compared to control group (healthy volunteer) were surveyed. In study of Mean age, mean weight and body mass index there were no significantly different between two groups.

The result of this study shown that serum levels of trace elements Zinc and Iron in patients with type 1 diabetes have a significant difference compared to 
control group. The serum levels of Iron and Zinc in the T1DM group had significant lower levels.

In fact it can be said that may result of difference in dietary Zinc intake in T1DM patients compared with non-diabetics. In addition to reduced intake, in case of zinc increased urine repulse in T1DM patients can be considered. On the other hand due to interference mechanisms of absorption, may be the absorption of Zinc and iron is influenced by each other.

Since reduced amounts of both elements in our study were reported, there are no alignment with other studies in this case.

The result of our study indicated that there is a significant negative correlation between the parameters of glycemic control (fructosamin and fasting blood sugar level) and serum Zinc levels in patients with T1DM. In fact in patients with poor glycemic control Zinc levels had lower level. In converse patients with good glycemic glycemic control have higher Zinc levels $(P<0.05)$. It is worth noting vegetarian diets and limited or unhealthy diet can cause effective change in the level of trace element such as Zinc and Iron.

Due to the impact of these factors on giving disease prevention and treatment strategies to reduce this problem in T1DM patient or even the role of their deficiencies in the etiology of T1DM can be noted that both issues are important.

Results obtained from statistical tests showed that in patient group, there is a positive correlation between age and Zinc level reduction. There was no significant correlation between studied parameters was considered in Iron status. The population of our study was from middle-aged and elderly women with T1DM, and should be considered that with aging, basal metabolism is reduced. This issue causes reduced absorption of microelements such as Zinc.

We can also acknowledge that this reduced level in zinc and iron level in patient group may be due to diminution in physical activity, poor and unhealthy diet in the case. For these reasons, dietary patterns will be changed at older ages $[26,27]$ in this regard using of various and complete regimes for these people may have appropriate consequences in the modification of decreased patterns of essential element such as Iron and Zinc. Depending on the type of participants in the study, confounded factors and Iron reducing factors, more Iron loss in women can be based on physiological principles mentioned.

However, further studies may able to answer more explicit to changes in Zinc and Iron in serum. In fact, the status of minerals in diabetic patients required clinical and extensive studies.

\section{Conclusions}

According to this study there is statistically significant difference between serum levels of iron and zinc in patients with type 1 diabetes compared to controls .indeed serum level of iron and zinc had lower level in patient group toward controls. In patients group, there are a positive correlation between age and decreased level of serum zinc $(P<0.05)$. Also there was a significant negative correlation between the glycemic control status and serum zinc. Other studied parameters concluded BMI (body mass index), Weight and height have not significant difference between groups. The decrease in serum iron and zinc level in women with type 1 diabetes may be related to low dietary intake or increased excretion of micro minerals or the presence of confounding factors that require more extensive intervention studies to confirm it.

\section{References}

[1] Atkinson, M. A., and Eisenbarth, G. S. 2001. "Type 1 Diabetes: New Perspectives on Disease Pathogenesis and Treatment." The Lancet 358 (9277): 221-9.

[2] De Block, C., De Leeuw, I., Vertommen, J., Rooman, R., Du Caju, M., Van Campenhout, C., Weyler, J. J., Winnock, F., Van Autreve, J. Gorus, F. K. and The Belgian Diabetes Registry. 2001. "Beta-Cell, Thyroid, Gastric, Adrenal and Coeliac Autoimmunity and Hla-Dq Types in Type 1 Diabetes.” Clinical and Experimental Immunology 126 (2): 236-41.

[3] Gorus, F., Goubert, P., Semakula, C., Vandewalle, C., De Schepper, J., Scheen, A., Christie, M. R., and Pipeleers, D. 

Iranian Elderly Women with Type 1 Diabetes Mellitus

G. 1997. "Ia-2-Autoantibodies Complement Gad65-Autoantibodies in New-Onset Iddm Patients and Help Predict Impending Diabetes in Their Sibling.s." Diabetologia 40 (1): 95-9.

[4] Suchkov, S., Gnatenko, D., Kostyushev, D., Paltsev, M., and Gadzhieva, S. 2011. "Preclinical and Predictive Algorithms in Monitoring Patients with AutoimmuneDiseases and Their Relatives-at-Risks." Russi: Intech Open Access Publisher 1-33.

[5] Abrams, P., De Leeuw, I., and Vertommen, J. 1996. "In New-Onset Insulin-Dependent Diabetic Patients the Presence of Anti-Thyroid Peroxidase Antibodies is Associated with Islet Cell Autoimmunity And the High Risk Haplotype Hla Dqa1 *0301-Dqb1* 0302." Diabetic Medicine 13 (5): 415-9.

[6] Karavanaki, K., Karayianni, C., Vassiliou, I., Tzanela, M., Sdogou, T., Kakleas, K., Tsentidis, C., Vakaki, M., Soldatou, A., Kallinikou, D., Kostaki, M., Tsitsopoulos, S., and Papathanasiou, A. 2014. "Multiple Autoimmunity, Type 1 Diabetes (T1dm), Autoimmune Thyroiditis and Thyroid Cancer: Is There an Association? A Case Report and Literature Review." Journal of Pediatric Endocrinology and Metabolism 27 (9-10): 1011-6.

[7] Maclaren, N. K., and Riley, W. J. 1985. "Thyroid, Gastric, and Adrenal Autoimmunities Associated with Insulin-Dependent Diabetes Mellitus.” Diabetes Care 8 (Supplement 1): 34-8.

[8] Betterle, C., Zanette, F., Pedini, B., Presotto, F., Rapp, L., Monciotti, C., and Rigon, F. 1984. "Clinical And Subclinical Organ-Specific Autoimmune Manifestations in Type 1 (Insulin-Dependent) Diabetic Patients and Their First-Degree Relatives." Diabetologia 26 (6): 431-6.

[9] Agzoub, M., Abdel-Hameed, A., and Bottazzo, G.,1994. "Prevalence of Islet Cell and Thyrogastric Autoantibodies in Sudanese Patients with Type 1 Diabetes." Diabetic Medicine 11 (2): 188-92.

[10] O'leary, C., Walsh, C., Wieneke, P., O'regan, P., Buckley, B., O'halloran, D., Ferriss, J. B., Quigley, E. M., Annis, P., Shanahan, F., and Cronin, C. C. 2002. "Coeliac Disease and Autoimmune Addison's Disease: A Clinical Pitfall." Qjm 95 (2): 79-82.

[11] Jehn, M., Clark, J.M., and Guallar, E., 2004. "Serum Ferritin and Risk of the Metabolic Syndrome in Us Adults." Diabetes Care 27 (10): 2422-8.

[12] Evangelopoulos, A. A., Vallianou, N. G., Panagiotakos, D. B., Georgiou, A., Zacharias, G. A., Alevra, A. N., Zalokosta, G. J., Vogiatzakis, E. D., and Avgerinos, P. C. 2008. "An Inverse Relationship Between Cumulating Components of the Metabolic Syndrome and Serum Magnesium Levels." Nutrition Research 28 (10): 659-63.

[13] Ganz, T., and Nemeth, E. 2006. "Iron Imports. Iv. Hepcidin and Regulation of Body Iron Metabolism."
American Journal of Physiology-Gastrointestinal and Liver Physiology 290 (2): G199-G203.

[14] Wish, J. B. 2006. “Assessing Iron Status: Beyond Serum Ferritin and Transferrin Saturation." Clinical Journal of the American Society of Nephrology 1 (Supplement 1): S4-S8.

[15] McClain, D., Abraham, D., Rogers, J., Brady, R., Gault, P., Ajioka, R., and Kushner, J. P. 2006. "High Prevalence of Abnormal Glucose Homeostasis Secondary to Decreased Insulin Secretion in Individuals With Hereditary Haemochromatosis.” Diabetologia 49 (7): 1661-9.

[16] Kundu, D., Roy, A., Mandal, T., Bandyopadhyay, U., Ghosh, E., and Ray, D. 2013. "Relation of Iron Stores to Oxidative Stress in Type 2 Diabetes.” Nigerian Journal of Clinical Practice 16 (1): 100-317.

[17] Haase, H., Overbeck, S., and Rink, L. 2008. "Zinc Supplementation for The Treatment or Prevention of Disease: Current Status and Future Perspectives." Experimental Gerontology 43 (5): 394-408.

[18] Fernández-Real, J. M., López-Bermejo, A., and Ricart, W. 2002. "Cross-Talk Between Iron Metabolism and Diabetes." Diabetes 51 (8): 2348-54.

[19] Walsh, C. T., Sandstead, H. H., Prasad, Ad. S., Newberne, P. M., and Fraker, P. J. 1994. "Zinc: Health Effects and Research Priorities for the 1990s." Environmental Health Perspectives102 (Suppl 2): 5.

[20] Serdar, M. A., Bakir, F., Haşimi, A., Çelik, T., Akin, O., Kenar, L., Aykut, O, and Yildirimkaya, M. 2009. "Trace and Toxic Element Patterns in Nonsmoker Patients with Noninsulin-Dependent Diabetes Mellitus, Impaired Glucose Tolerance, and Fasting Glucose." International Journal of Diabetes in Developing Countries 29 (1): 35.

[21] Wijesekara, N., Chimienti, F., and Wheeler, M. 2009. "Zinc, a Regulator of Islet Function and Glucose Homeostasis." Diabetes, Obesity and Metabolism 11 (s4): 202-14.

[22] Wiernsperger, N., and Rapin, J. 2010. "Trace Elementsin Glucometabolic Disorders: An Update." Diabetol Metab Syndr 2 (70): 1-9

[23] Kaneto, H., Katakami, N., Matsuhisa, M., and Matsuoka, T-a. 2010. "Role of Reactive Oxygen Species in the Progression of Type 2 Diabetes and Atherosclerosis." Mediators of Inflammation 2010.

[24] Chausmer, A. B. 1998. "Zinc, Insulin andDiabetes." Journal of the American College of Nutrition 17 (2): 109-15.

[25] D'Ocon, C., AlonsodA. V., and Frasquet, I. 1987. "Levels of $\mathrm{Zn}$ and $\mathrm{Cu}$ in the Serum of a Diabetic Population." Revista Espanola De Fisiologia 43 (3): 335-8.

[26] Worwood, M. 2002. "Serum Transferrin Receptor Assays and Their Application." Annals of Clinical Biochemistry 39 (3): 221-30. 

Iranian Elderly Women with Type 1 Diabetes Mellitus

[27] Jiang, R., Manson, J. E., Meigs. J. B., Ma, J., Rifai, N., and Hu, F. B. 2004. "Body Iron Stores in Relation to Risk of
Type 2 Diabetes in Apparently Healthy Women." Jama 291 (6): 711. 